\title{
Adsorption Kinetics and Evaluation Study of Iron Oxide Nanoparticles Impregnated in Polyurethane Matrix for Water Filtration Application
}

\author{
Faten B. Hussein, Nidal H. Abu-Zahra \\ Materials Science and Engineering Department, University of Wisconsin-Milwaukee, Milwaukee, WI, USA \\ Email: fhussein@uwm.edu,nidal@uwm.edu
}

How to cite this paper: Hussein, F.B. and Abu-Zahra, N.H. (2017) Adsorption Kinetics and Evaluation Study of Iron Oxide Nanoparticles Impregnated in Polyurethane Matrix for Water Filtration Application. Journal of Minerals and Materials Characterization and Engineering, 5, 298-310. https://doi.org/10.4236/jmmce.2017.55025

Received: August 17, 2017

Accepted: September 11, 2017

Published: September 14, 2017

Copyright $\odot 2017$ by authors and Scientific Research Publishing Inc. This work is licensed under the Creative Commons Attribution International License (CC BY 4.0).

http://creativecommons.org/licenses/by/4.0/

(c) (i) Open Access

\begin{abstract}
A polyurethane (PU) foam composite, loaded with iron oxide nanoparticles (IONPs), was developed for arsenic removal from drinking water at low concentrations. The effect of various synthesis parameters such as the size of IONPs and the foam shape, on the performance of the adsorbents in removing arsenic was investigated. To examine the surface adsorption of arsenic species, Energy Dispersive X-ray Microscopy (EDX) was utilized. Mercury Porosimetry was used to analyze the porosity and density of the PU-IONPs nanocomposites. Atomic Absorption Spectrometry (AAS) was conducted to measure the arsenic concentration in the treated solutions. Kinetic models were applied to determine the mechanisms which control the adsorption process. A pseudo-second-order model was found to be the best fit model for the adsorption data. Experimental results revealed that decreasing the size of IONPs from $50-100 \mathrm{~nm}$ to $15-20 \mathrm{~nm}$ yields a higher removal capacity. In addition, granular adsorbents exhibit higher removal capacity compared to cubical shaped adsorbents in the order of $20 \%-100 \%$.
\end{abstract}

\section{Keywords}

Adsorption Kinetics, Iron Oxide, Polyurethane, Water Filtration

\section{Introduction}

Heavy metal pollutants such as Lead, Arsenic, Cadmium, and Mercury are the main sources of water contamination. They have serious toxic effects on humans and living organisms. Arsenic contamination of ground water poses a serious concern in many countries throughout the world, including the United States. 
The contamination level is variably defined to be greater than $10 \mu \mathrm{g} / \mathrm{L}$ or greater than $50 \mu \mathrm{g} / \mathrm{L}$ by different agencies [1]. High concentration of arsenic in drinking water causes acute and chronic damage to the central and peripheral nervous systems, as well as, the dermal, cardiovascular, gastrointestinal, and respiratory systems [2]. Extensive research work has been conducted to find and develop many separation and treatment techniques.

The removal of arsenic species involves a selective separation of arsenate As (V) and arsenite As (III). The conventional treatment methods of arsenic involve a coagulation with ferric chloride or aluminum sulphate coagulants, followed by the separation of insoluble product by settling or by direct filtration through sand beds [3] [4] [5]. Other treatment techniques for arsenic removal are lime softening, flotation and adsorption on hydrated iron oxide or activated carbon, ion exchange, and reverse osmosis [6]-[12]. These techniques have been reported to be effective mainly for the removal of As (V). Therefore, a pre-oxidation step is typically required in order to attain efficient removal of As (III). Solid nano adsorbents are becoming the core of most recent studies in removing heavy metals due to their high capacity and affinity to heavy metal ions. Nano adsorbents such as HFO [13] and MgO [14], have been deposited on the surface of porous materials such as polymeric anion exchanger D-201 [13] and polyurethane foam [14], or incorporated inside electro spun polymers [15] [16] [17]. Nevertheless, the preparation of these adsorbents usually requires complicated and costly methods.

In this study, a new bulk modified nanocomposite material (adsorbent) is developed by loading iron oxide nanoparticles (IONPs) inside a polyurethane (PU) foam matrix. This allows for exploiting the inherent advantages of porous PU foam structures and flexibility, combined with the functionality of the adsorbent nano particles imbedded in the foam media, which facilitate the post treatment step in the filtration system. The ability of iron compounds to react with arsenic species by adsorption and ion exchange mechanisms increases the arsenic removal capacity.

\section{Experimental}

\subsection{Materials}

For the synthesis of PU-IONPs nanocomposite, the following raw materials were used as received: toluene di-isocyanate (TDI; 2.4\% - 80\%, 2.6\% - 20\%, Alfa Aesar), polysiloxane surfactant (Sigma Aldrich), nitrogen gas (Airgas, $\mathrm{O}_{2}$ free UHP), iron oxide nanoparticles (IONPs; $\mathrm{Fe}_{3} \mathrm{O}_{4}$, high purity 99.5\%, US Research Nanomaterials Inc.) with two size ranges: 50 - $100 \mathrm{~nm}$ and $15-20 \mathrm{~nm}, 18.2$ MOhm-cm deionized water, and polypropylene glycol 1200 (PPG; Sigma Aldrich Co. LLC) dehumidified in a vacuum oven at $70^{\circ} \mathrm{C} .1 \mathrm{ppm}$ standard arsenic solution, from Inorganic Ventures Co., was diluted to $100 \mathrm{ppb}$. The solution contained both As (III) \& As (V) at pH 6.5. 


\subsection{Synthesis and Characterization of PU Nanocomposite}

The experimental setup described in this study is designated in a previous publication [18]. A 3-neck round bottom reaction flask was placed in an oil bath and fitted with a mechanical stirrer and a condenser at the center neck. A nitrogen gas inlet was fitted at the right neck and a dropping funnel was fitted at the left neck. The reaction between PPG and TDI was conducted at $75^{\circ} \mathrm{C}$ in an inert atmosphere. At first, the 3-neck flask was filled with TDI and allowed to stabilize at $75^{\circ} \mathrm{C}$ in a saturated nitrogen atmosphere; a pre-weighted amount of PPG was added dropwise and allowed to react with TDI for 4 - 5 hours until an initial isocyanate content of $11 \%-12 \%$ is reached. IONPs were manually added with $12 \mathrm{wt} \%$ of the PU mixture. Based on the amount of PPG used, a pre-weighted amount of deionized water was added as a blowing agent along with the polysiloxane surfactant. The compound was mixed using a mechanical stirrer at 2500 $3000 \mathrm{rpm}$ for 10 - 15 seconds. The reaction of water with the remaining isocyanate groups released $\mathrm{CO}_{2}$ gas to form the final foam structure [19].

Many samples were prepared using two PPG: TDI ratios; 1:1.75 and 1:2, and two sizes of IONPs; $15-20 \mathrm{~nm}$ and $50-100 \mathrm{~nm}$. The optimal loading percentage of IONPs was determined to be $12 \mathrm{wt} \%$ [20] [21], where less than $12 \mathrm{wt} \%$ results in lower removal capacity of As and more than $12 \mathrm{wt} \%$ did not improve the removal capacity significantly. The elemental analysis of PU nanocomposite foam was inspected using HITACHI S-4800 (SEM/EDX). Measurements of porosity-related characteristics were conducted for both 1:1.75 and 1:2 PPG:TDI compositions via MicroActive AutoPore V 9600. The adsorption capacity of the foam was measured with a Thermo Electron Corporation S4 Atomic Absorption Spectrometer (AAS) at the minimum detection limit of $0.2 \mathrm{ppb}$.

\subsection{Adsorption Studies}

Batch mode experiments were conducted in two stages. In the first stage, $1 \mathrm{~g} \mathrm{cu}$ bic samples with PPG:TDI ratios; 1:1.75 and 1:2, and two sizes of IONPs; 15 - 20 $\mathrm{nm}$ and $50-100 \mathrm{~nm}$, were soaked in $50 \mathrm{ml}$ of $100 \mathrm{ppb}$ As solution for 6 and 24 hours. The cubes were shaken in neutral solution $(\mathrm{pH}=6.5)$ at $200 \mathrm{rpm}$ and at room temperature $\left(22^{\circ} \mathrm{C}\right)$. The purpose of the first stage is to study the effect of the IONPs size on the arsenic removal capacity. In the second stage, samples with different shapes; i.e., cube and granular, were used in similar conditions of the first stage to investigate the effect of the foam shape on the adsorption capacity. After each batch test, $25 \mathrm{ml}$ of each treated solution was filtered and preserved with $2 \% \mathrm{HNO}_{3}$ for AAS analysis. Additionally, three sets of samples were prepared to investigate the adsorption kinetics. Samples with PPG:TDI ratios; 1:1.75 and 1:2, and one foam shape (cube), were stirred under the same conditions, as the previous batches, between 3-hrs and 24-hrs at 3-hr intervals. This stage was aimed to study the effect of PU compositions on the adsorption kinetics. Moreover, foam samples with PPG:TDI ratio of 1:1.75, and different shapes (cube and granular), were used to study the effect of the foam shape on its kinet- 
ic behavior. Figure 1 shows the experiment levels of the various PU foam samples prepared for this study.

\section{Results and Discussion}

\subsection{PU-IONPs Foam Characterization}

\subsubsection{EDX Analysis}

To enhance the EDX analysis, the foam samples were coated using a gold sputter coater (Denton Desk II Cold Sputter/Etch unit). In Figure 2, the EDX elemental analysis, which was performed on the adsorbent foam before and after soaking in a $100 \mathrm{ppb}$ standard As solution, shows the presence of arsenic in the bulk of the foam samples, along with the original elements of PU-IONPs foam composition (i.e., Carbon, Oxygen, and Iron). In previous research work [21], the porous structure of PU-IONPs foam samples with a combination of open and closed cells was depicted. The observed structure exhibits higher surface area with imbedded IONPs compared to deposited nanoparticle on the foam surface [22]. The adsorption capacity for the arsenic species will be enhanced with higher surface areas of IONPs exposed to the contaminants.

\subsubsection{Porosity and Density}

The measurements of porosity and density were conducted for both 1:1.75 and 1:2 PPG:TDI compositions. MicroActive AutoPore IV 9600 was used to measure the nanocomposite foam porosity by applying various levels of pressure to foam samples immersed in mercury. Table 1 summarizes the bulk density, total

Table 1. PU-IONPs porosity-related characteristics.

\begin{tabular}{cccc}
\hline PPG: TDI & Bulk Density $(\mathrm{g} / \mathrm{ml})$ & Total Pore Area $\left(\mathrm{m}^{2} / \mathrm{g}\right)$ & Porosity $(\%)$ \\
\hline $1: 2$ & 0.925 & 28.48 & 8.26 \\
$1: 1.75$ & 1.17 & 40.16 & 10.17 \\
\hline
\end{tabular}

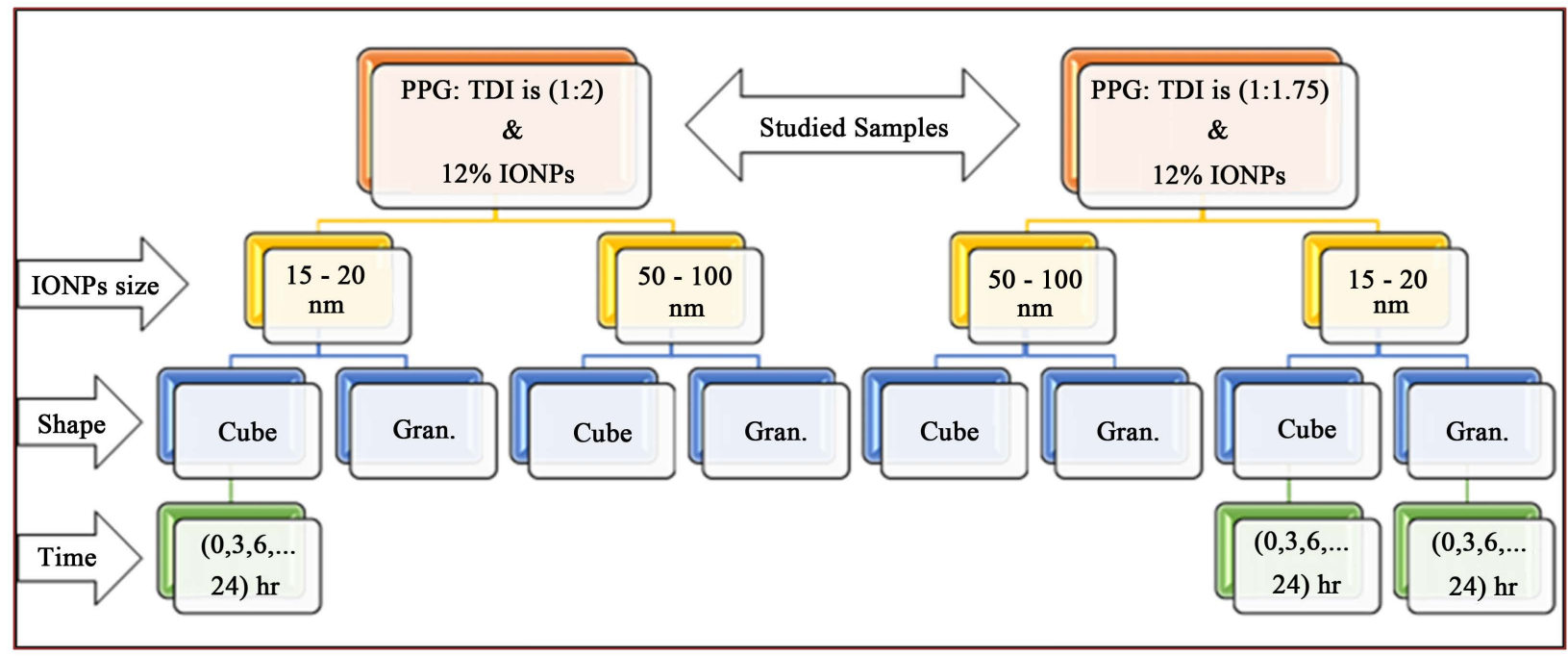

Figure 1. PU-IONPs foam samples for adsorption studies. 


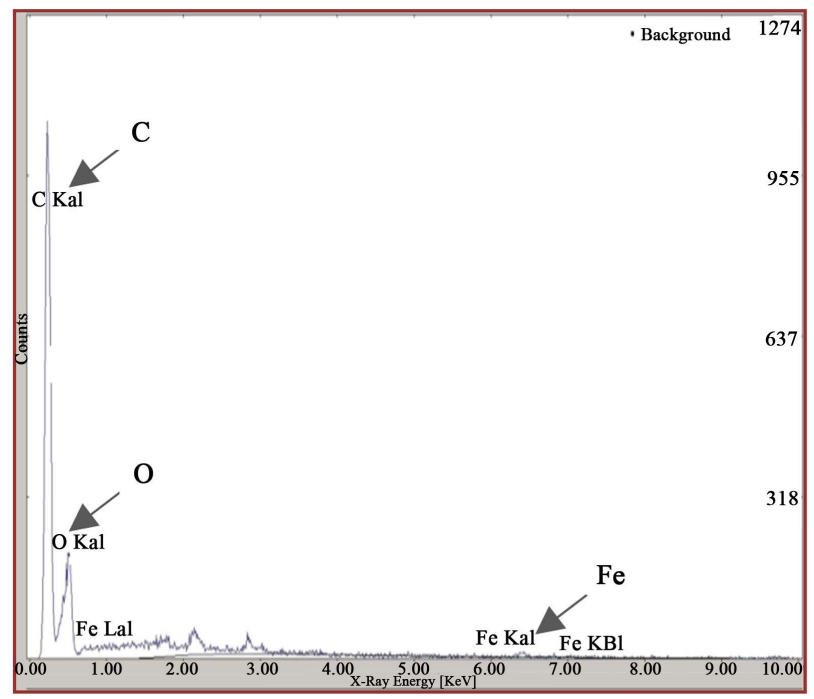

(a)

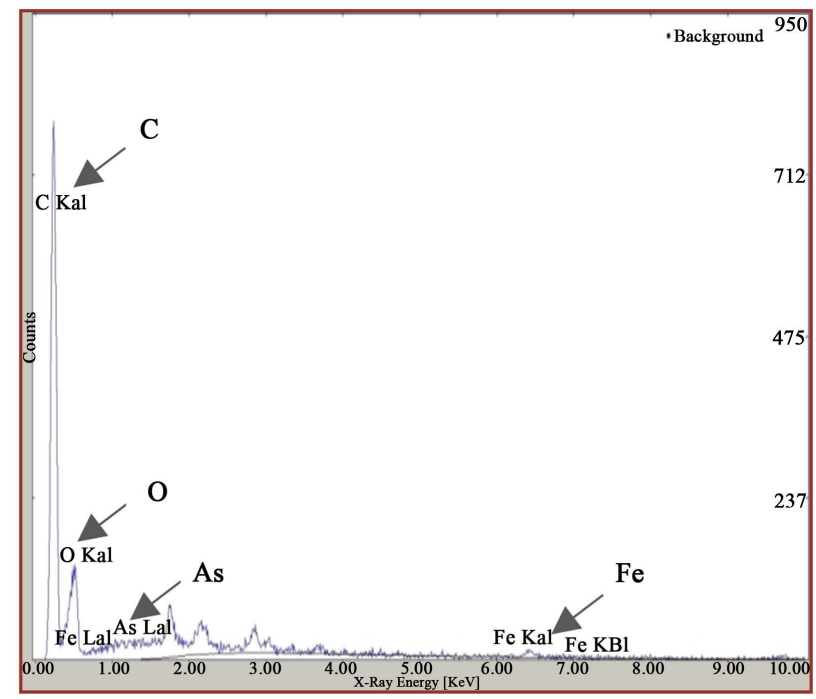

(b)

Figure 2. EDX elemental analysis, (a) PU-IONPs adsorbent before exposure to As solution; (b) PU-IONPs adsorbent after exposure to As solution.

pore area, and porosity for both PU compositions. Figure 3 shows the cumulative mercury intrusions versus the pore size diameter for both compositions.

PU foams with PPG: TDI of 1:1.75 exhibit higher bulk density compared to those with PPG:TDI of 1:2. In addition, the total pore area and porosity were found to be greater in PPG:TDI (1:1.75). This can be attributed to the physical properties of each material component in the mixture such as density and viscosity.

\subsection{Batch Adsorption Analysis}

First batch experiments were performed, under the same exposure conditions, to investigate the effect of IONPs size on the As removal capacity of the PU nanocomposite foams. The foam samples were prepared with the optimum percentage of loaded IONPs (12\%) using both PPG:TDI composition ratios; 1:2 and 1:1.75, and two size ranges of the IONPs; $15-20 \mathrm{~nm}$ and $50-100 \mathrm{~nm}$. The sorption batch experiments were carried out under two exposure time intervals; $6 \mathrm{hr}$ and $24 \mathrm{hr}$. Figure 4 shows the As removal capacity for the various IONPs sizes and exposure times.

The results shown in Figure 4 indicate an improvement in the performance of the adsorbents when the size of IONPs is decreased from $50-100 \mathrm{~nm}$ to $15-20$ $\mathrm{nm}$ for both compositions (PPG:TDI 1:2 and 1:1.75). This behavior can be attributed to the higher surface area provided with the smaller size particles and the weaker effect of self-aggregation of the nanoparticles [23] [24]. Additionally, by allowing more contact time between the arsenic species and the adsorbent surface, a higher removal capacity can be achieved due to the filling of the available binding sites on the surface.

To study the effect of shape on the adsorption capacity, foam samples with a 


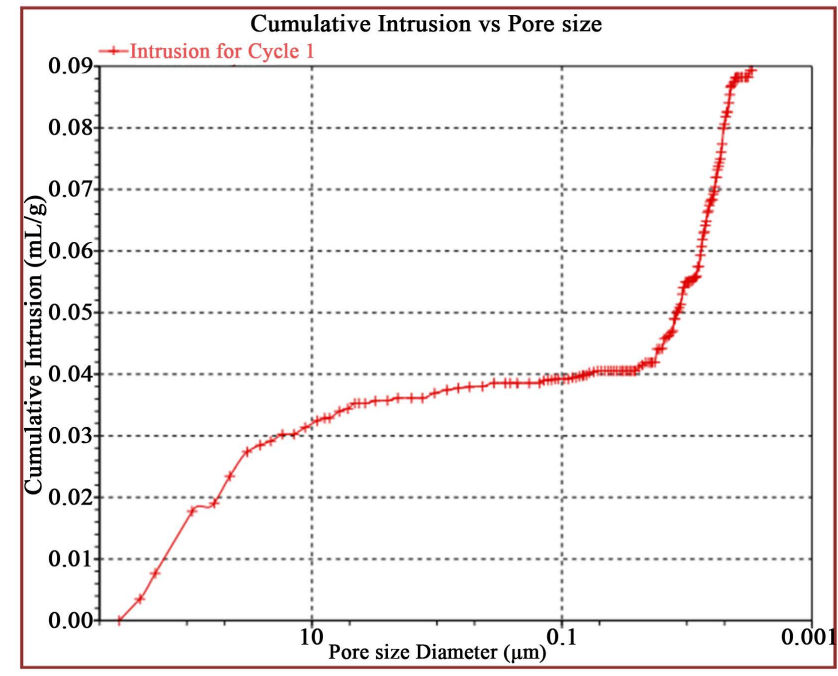

(a)

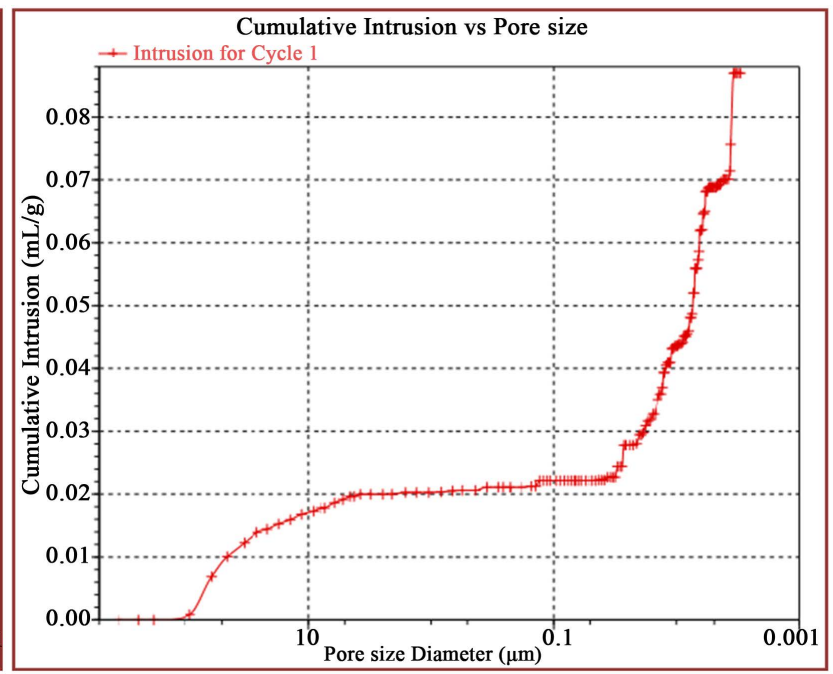

(b)

Figure 3. Cumulative mercury intrusion vs. pore size diameter. (a) PPG:TDI 1:2; (b) PPG:TDI 1:1.75.

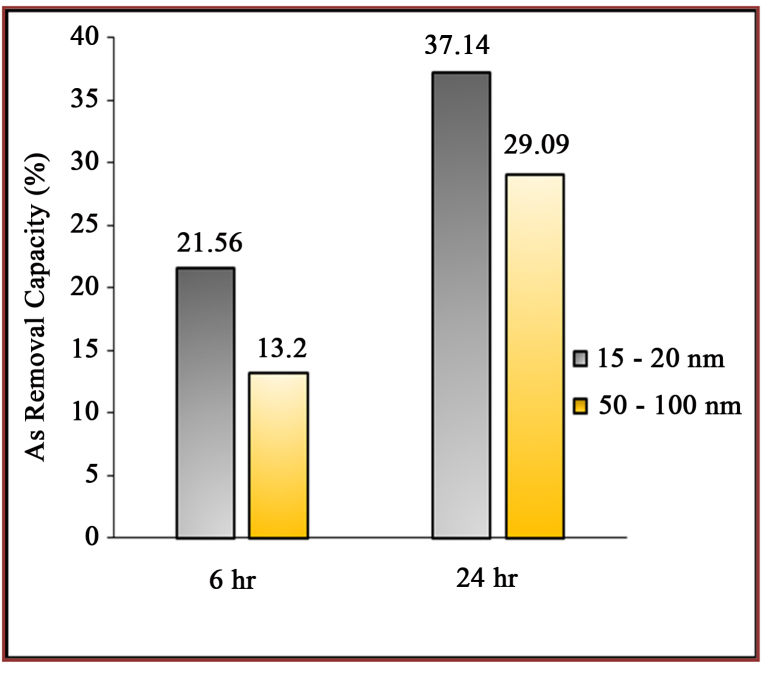

(a)

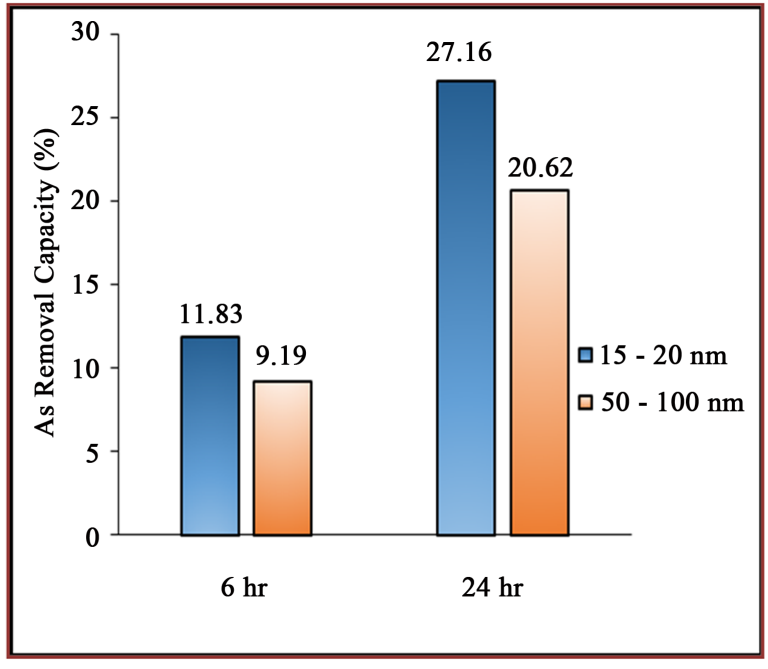

(b)

Figure 4. (a) Arsenic removal capacity of composition ratio 1:2 (PPG:TDI) Cube; (b) Arsenic removal capacity of composition ratio 1:1.75 (PPG:TDI) Cube, with two size ranges of IONPs; $15-20 \mathrm{~nm}$ and $50-100 \mathrm{~nm}$.

granular shape were prepared with $12 \mathrm{wt} \%$ loaded IONPs using both PPG:TDI composition ratios and IONP sizes; under similar exposure conditions of the first stage. Figure 5 illustrates the removal capacity of granular PU-IONPs adsorbents.

The outcomes of second batch of experiments reveal an increase in the adsorption capacity of both compositions (PPG:TDI 1:2 and 1:1.75) and IONP sizes $(15-20 \mathrm{~nm}$ and $50-100 \mathrm{~nm})$ compared to the first stage at both exposure times. Foam samples with the granular form provide more contact sites on the surface of adsorbent than the cubic one; therefore, more arsenic species can be trapped by an adsorption mechanism. The increase in the As removal capacity, for all samples, is calculated and listed in Table 2. 


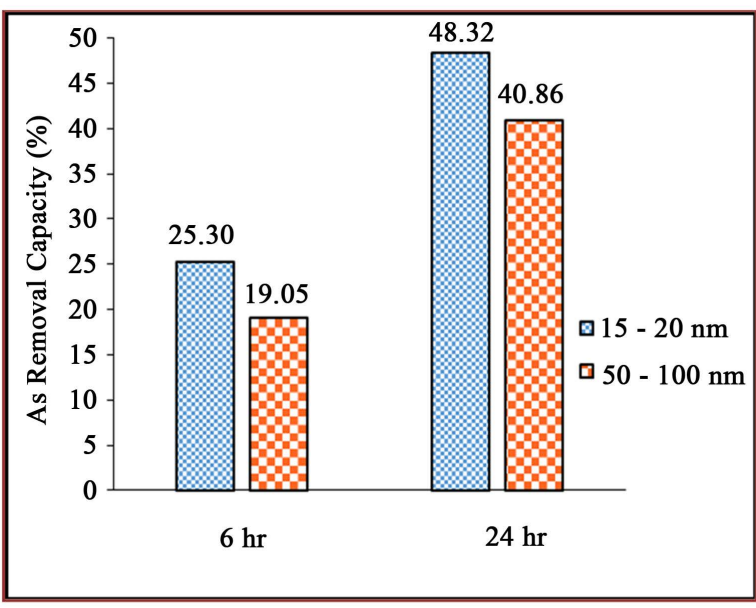

(a)

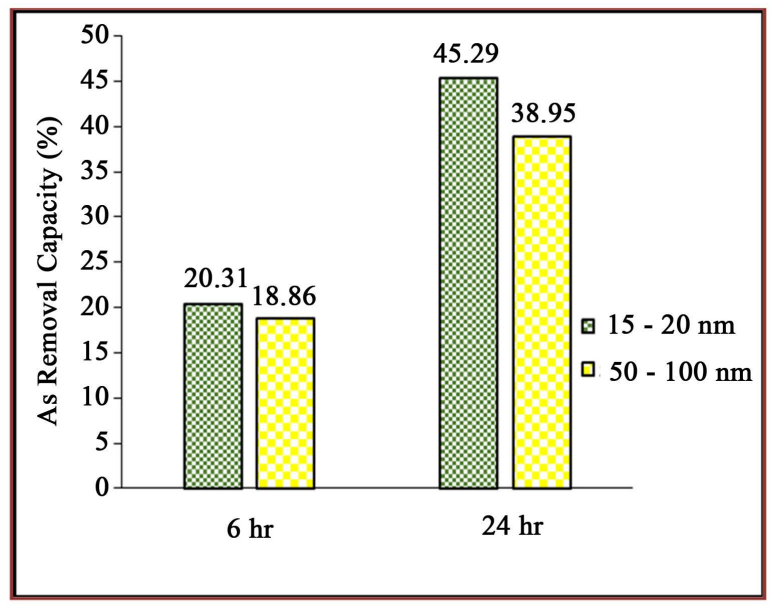

(b)

Figure 5. (a) Arsenic removal capacity of composition ratio 1:2 (PPG:TDI) granular; (b) Arsenic removal capacity of composition ratio 1:1.75 (PPG:TDI) granular, with granular shape and two size ranges of IONPs; $15-20 \mathrm{~nm}$ and $50-100 \mathrm{~nm}$.

Table 2. The effect of granular shape on the removal capacity of arsenic.

\begin{tabular}{cccc}
\hline Molar Ratio of (PPG:TDI) & IONPs Size (nm) & Contact Time (hr) & Increase Percentage (\%) \\
\hline \multirow{2}{*}{$1: 2$} & $15-20$ & 6 & 17.35 \\
& $50-100$ & 24 & 30.1 \\
& & 6 & 44.32 \\
$15-20$ & 24 & 40.46 \\
& & 6 & 71.68 \\
& & 24 & 66.75 \\
& $50-1.75$ & 6 & 88.89 \\
\hline
\end{tabular}

Varying the shape of foam from a cubic to a granular form affects the removal capacity of the adsorbent. It can be noticed that the increase ranges, approximately, between 20\% in the case of PPG:TDI (1:2), 15 - $20 \mathrm{~nm}$ IONPs, and $6 \mathrm{hr}$ contact time, and 100\% in the case of PPG:TDI (1:1.75), 50 - $100 \mathrm{~nm}$ IONPs, and $24 \mathrm{hr}$ contact time. Also, the difference in removal capacity for both PPG:TDI compositions, when they were used as cubic shape compared to granular, is eliminated. In other words, the effect of the difference in the foam cellular structure for both compositions is degraded by altering the adsorbent shape from cubic to granular.

\subsection{Contact Time and Adsorption Kinetics Studies}

The effect of contact time on the removal capacity of arsenic was studied in the range of $3 \mathrm{hr}$ to $24 \mathrm{hr}$ exposure time. One gram foam samples of three different types of adsorbents; (a) PPG:TDI ratio (1:2)-Cube, (b) PPG:TDI ratio (1:1.75)-Cube, and (c) PPG:TDI (1:1.75)-Granular were used. Figure 6 shows the time 


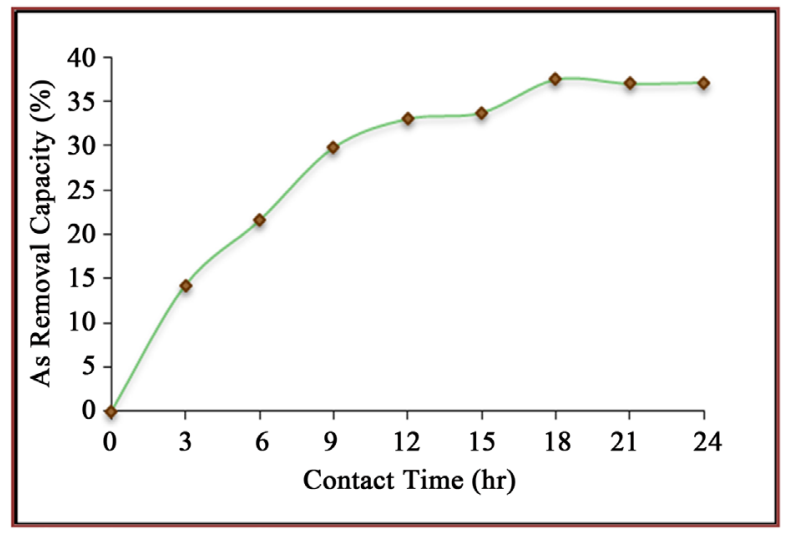

(a)

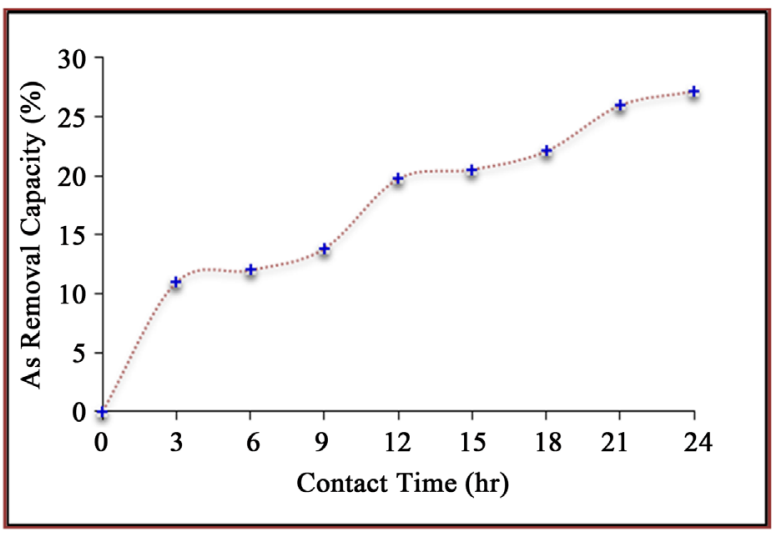

(b)

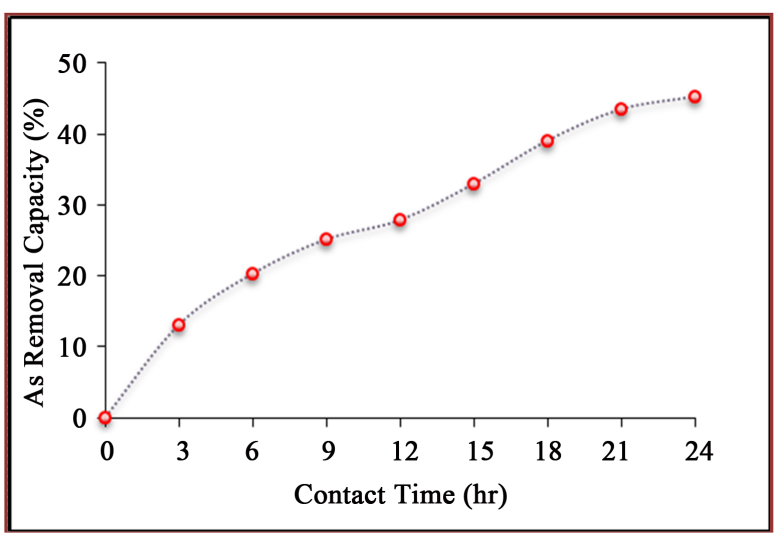

(c)

Figure 6. Effect of contact time on the removal capacity of As, using (a) PPG:TDI ratio (1:2)-Cube; (b) PPG:TDI ratio (1:1.75)-Cube; and (c) PPG:TDI ratio (1:1.75)-Granular.

profile of arsenic adsorption on PU-IONPs nanocomposite with an initial concentration of $100 \mathrm{ppb}$.

The experimental outcomes indicate that the uptake of As increases with time. However, the rate of adsorption was rapid in the first $12 \mathrm{hr}$ after which the rate slowed down as the equilibrium state was approached. The highest removal capacity occurred at $24 \mathrm{hr}$ for all adsorbents; $45.29 \%, 37.14 \%$, and $27.16 \%$ removal capacities were achieved for PPG:TDI (1:1.75)-Granular, PPG:TDI ratio (1:2)-Cube, and PPG:TDI (1:1.75)-Granular; respectively.

In order to examine the kinetic mechanism which controls the adsorption process, several kinetic models like Lagergren pseudo-first-order [25] and pseudo-second-order [26] were tested to interpret the experimental data. The integrated linear pseudo-first-order rate equation can be represented as:

$$
\log \left(q_{e}-q_{t}\right)=\log q_{e}-\left(K_{1} / 2.303\right) t
$$

where $q_{e}$ is the amount of As adsorbed $(\mathrm{mg} / \mathrm{g})$ at equilibrium, $q_{t}$ is the amount of As adsorbed $(\mathrm{mg} / \mathrm{g})$ at any time " $t$ ". $K_{1}$ is the pseudo-first-order rate constant $\left(\mathrm{hr}^{-1}\right)$. The plot of $\log \left(q_{e}-q_{t}\right)$ vs. $t$ gives a linear representation of Lagergren pseudo-first-order as illustrated in Figure 7. The values of $K_{1}$ were obtained from the slope of $\log \left(q_{e}-q_{t}\right)$ vs. $t$ plots. 


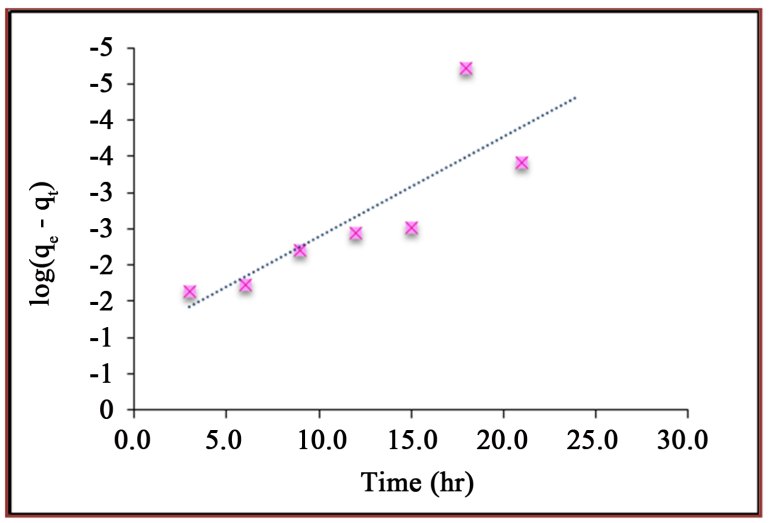

(a)

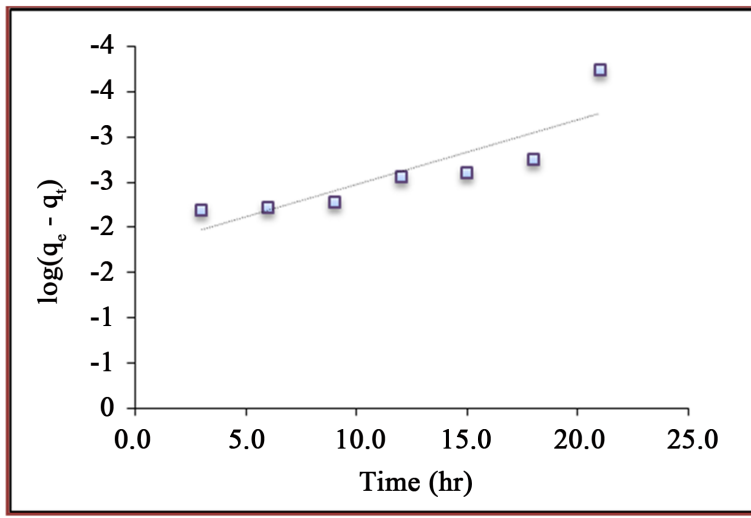

(b)

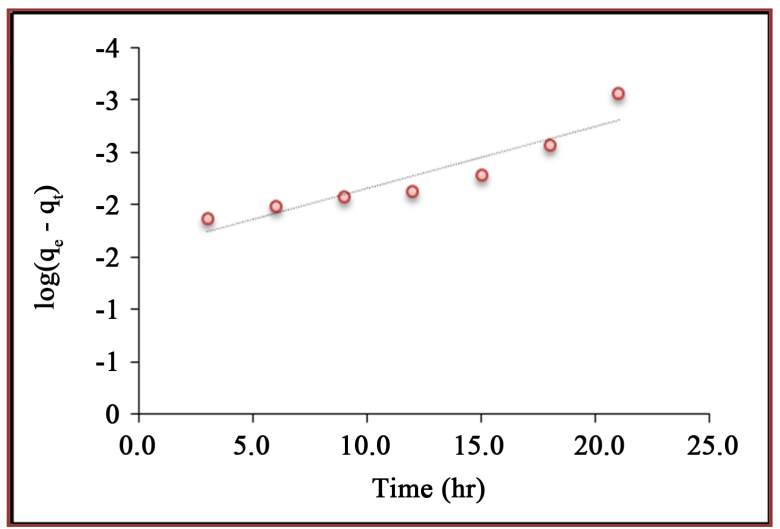

(c)

Figure 7. Pseudo-first-order kinetics for (a) PPG:TDI ratio (1:2)-Cube; (b) PPG:TDI ratio (1:1.75)-Cube; and (c) PPG:TDI ratio (1:1.75)-Granular.

The linear form of pseudo-second-order rate equation is represented by:

$$
1 / q_{t}=1 /\left(K_{2} q_{e}^{2}\right) t+1 / q_{e}
$$

where $q_{t}$ is the amount of As adsorbed $(\mathrm{mg} / \mathrm{g})$ at any time " $t$ ", $q_{e}$ is the amount of As adsorbed $(\mathrm{mg} / \mathrm{g})$ at equilibrium. $K_{2}$ is the pseudo-second-order rate constant (g/mg.hr $\left.{ }^{-1}\right)$. The experimental data plotted against $1 / q_{t}$ vs. $1 / t$ is shown in Figure 8; $K_{2}$ and $q_{e}$ were calculated from the slope and intercept of these plots. Table 3 summarizes the calculated values of $K_{1}, K_{2}, q_{e}$, and $R^{2}$ for both kinetic models.

The evaluation of the best fit kinetic models was made based on $R^{2}$ values. The calculated values of $R^{2}$ for the pseudo-second-order are higher than the pseudo-first-order. Hence, the second order kinetic model better represented the adsorption kinetics, suggesting that the adsorption process is more likely to be a chemisorption. The adsorption behavior may involve valence forces through the sharing of electrons between arsenic and the adsorbent [26]. Furthermore, previous investigations support that a second order kinetic model correlates well with the experimental data of arsenic adsorption [27] [28] [29] [30]. Adsorbent (a); PPG:TDI ratio (1:2)-Cube fits better than adsorbent (b); PPG:TDI (1:1.75)-Cube, while Adsorbent (c); PPG:TDI (1:1.75)-Granular fits better than adsorbent (b) and (a); respectively. 


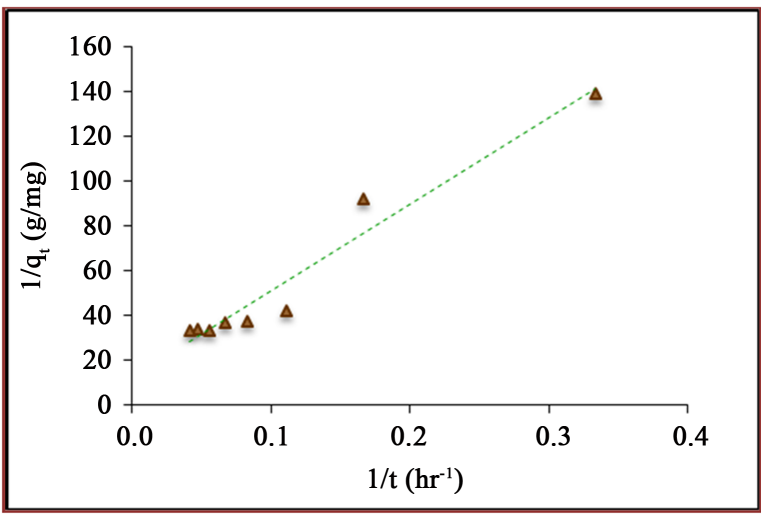

(a)

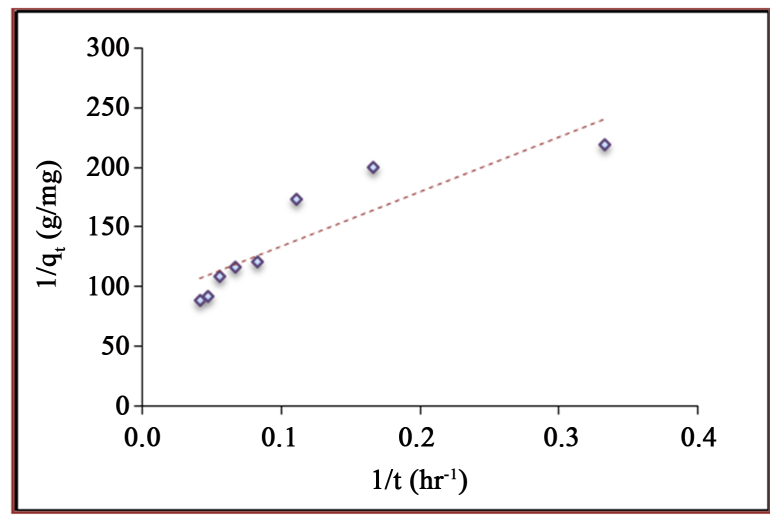

(b)

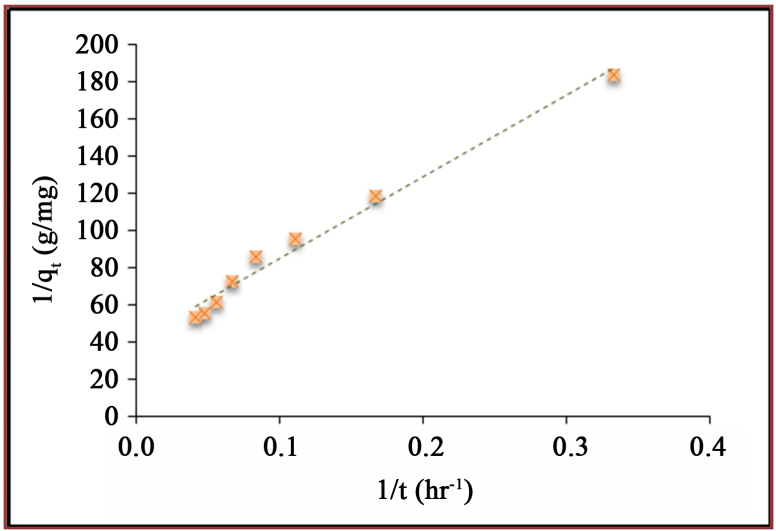

(c)

Figure 8. Pseudo-second-order kinetics for (a) PPG:TDI ratio (1:2)-Cube; (b) PPG:TDI ratio (1:1.75)-Cube; and (c) PPG:TDI ratio (1:1.75)-Granular.

Table 3. Kinetic models rate constants $\left(K_{1}\right)$ and $\left(K_{2}\right)$.

\begin{tabular}{cccccc}
\hline \multirow{2}{*}{ Type of Adsorbent } & \multicolumn{2}{c}{ Pseudo first order } & \multicolumn{3}{c}{ Pseudo second order } \\
\cline { 2 - 6 } & $K_{1}\left(\mathrm{hr}^{-1}\right)$ & $R^{2}$ & $K_{2}\left(\mathrm{~g} / \mathrm{mg} \cdot \mathrm{hr}^{-1}\right)$ & $q_{e}(\mathrm{mg} / \mathrm{g})$ & $R^{2}$ \\
\hline (a) & 0.32 & 0.690 & 0.38 & 0.082 & 0.953 \\
(b) & 0.16 & 0.749 & 17.01 & 0.011 & 0.793 \\
(c) & 0.14 & 0.864 & 3.77 & 0.025 & 0.982 \\
\hline
\end{tabular}

\section{Conclusions}

The present study introduces a new bulk modified nanocomposite material by using IONPs impregnated in PU foam for arsenic removal. Adsorption batch experiments were performed to investigate the effect of IONPs size on the removal capacity of the adsorbent foams. Foam samples with a smaller IONPs size range (15- $20 \mathrm{~nm}$ ) achieved higher removal capacity compared to a size range of $50-100 \mathrm{~nm}$. In addition, the foam shape effect is evaluated; granular adsorbents exhibit a higher removal capacity compared to cubic adsorbents. The increase percentage ranged between 20\% in the case of PPG:TDI (1:2), $15-20 \mathrm{~nm}$ IONPs, and $6 \mathrm{hr}$ contact time, and 100\% in the case of PPG:TDI (1:1.75), $50-100 \mathrm{~nm}$ 
IONPs, and $24 \mathrm{hr}$ contact time. The kinetic data correlates well with a pseudo-second-order-kinetic model. Adsorbents with a PPG:TDI ratio (1:2) fit better than adsorbents with a PPG:TDI ratio (1:1.75). Adsorbents with a granular form fit better than adsorbents with a cubic form. The proposed system of the nanocomposite foam offers a potential for the removal of arsenic with higher capacity at lower costs than conventional arsenic removal systems.

\section{Acknowledgements}

We would like to thank Dr. Steven Hardcastle and Mr. Daniel Kaminski at the Advanced Analysis Facility (AAF) for their assistance in the foam characterization. In addition, we would like to thank Dr. Subhashini Gunashekar for her assistance in the foam synthesis.

\section{References}

[1] Smedley, P.L. and Kinniburgh, D.G. (2002) A Review of the Source, Behavior and Distribution of Arsenic in Natural Waters. Applied Geochemistry, 17, 517-568. https://doi.org/10.1016/S0883-2927(02)00018-5

[2] Ferrante, M., Conti, G. and Rasic-Milutinovic, Z. (2013) Health Effects of Metals and Related Substances in Drinking Water. IWA Publishing, London.

[3] Zouboulis, A. and Katsoyiannis, I. (2002) Removal of Arsenates from Contaminated Water by Coagulation-Direct Filtration. Separation Science and Technology, 37, 2859-2873. https://doi.org/10.1081/SS-120005470

[4] Baskan, M. and Pala, A. (2010) A Statistical Experiment Design Approach for Arsenic Removal by Coagulation Process Using Aluminum Sulfate. Desalination, 254, 42-48. https://doi.org/10.1016/j.desal.2009.12.016

[5] Wang, Y., Duan, J., Liu, S., Li, W., Leeuwen, J. and Mulcahy, D. (2014) Removal of As(III) and As(V) by Ferric Salts Coagulation-Implications of Particle Size and Zeta Potential of Precipitates. Separation and Purification Technology, 135, 64-71. https://doi.org/10.1016/j.seppur.2014.08.004

[6] Gu, Z.M., Fang, J. and Deng, B.L. (2005) Preparation and Evaluation of GAC-Based Iron-Containing Adsorbents for Arsenic Removal. Environmental Science \& Technology, 39, 3833-3843. https://doi.org/10.1021/es048179r

[7] Gupta, V.K., Saini, V.K. and Jain, N. (2005) Adsorption of As(III) from Aqueous Solutions by Iron-Oxide Coated Sand. Journal of Colloid and Interface Science, 288, 55-60. https://doi.org/10.1016/j.jcis.2005.02.054

[8] DeMarco, M.J., SenGupta, A.K. and Greenleaf, J.E. (2003) Arsenic Removal Using a Polymeric/Inorganic Hybrid Sorbent. Water Research, 37, 164-176. https://doi.org/10.1016/S0043-1354(02)00238-5

[9] Asadullah, M., Jahan, I., Ahmed, M., Adawiyah, P., Malek, N. and Rahman, M. (2014) Preparation of Microporous Activated Carbon and Its Modification for Arsenic Removal from Water. Journal of Industrial and Engineering Chemistry, 20, 887-896. https://doi.org/10.1016/j.jiec.2013.06.019

[10] Ning, R. (2002) Arsenic Removal by Reverse Osmosis. Desalination, 143, 273-241. https://doi.org/10.1016/S0011-9164(02)00262-X

[11] McNeill, L. and Edwards, M. (1997) Arsenic Removal during Precipitative Softening. Journal of Environmental Engineering, 123, 453-460. 
https://doi.org/10.1061/(ASCE)0733-9372(1997)123:5(453)

[12] Altundoğan, H., Altundoğan, S., Tümen, F. and Bildik, M. (2000) Arsenic Removal from Aqueous Solutions by Adsorption on Red Mud. Waste Management, 20, 761-767. https://doi.org/10.1016/S0956-053X(00)00031-3

[13] Zhang, Q.J., Pan, B.C., Zhang, W., Bingjun Pan, B.J., Zhang, Q.X. and Ren, H. (2008) Arsenate Removal from Aqueous Media by Nanosized Hydrated Ferric Oxide (HFO)-Loaded Polymeric Sorbents: Effect of HFO Loadings. Industrial \& Engineering Chemistry Research, 47, 3957-3962. https://doi.org/10.1021/ie800275k

[14] Choi, H., Woo, N., Jang, M., Cannon, F. and Snyder, S. (2014) Magnesium Oxide Impregnated Polyurethane to Remove High Levels of Manganese Cations from Water. Separation and Purification Technology, 136, 184-189. https://doi.org/10.1016/j.seppur.2014.08.037

[15] Hristovski, K., Westerhoff, P., Crittenden, J. and Olson, L. (2008) Arsenate Removal by Nanostructured $\mathrm{ZrO}_{2}$ Spheres. Environmental Science \& Technology, 42, 3786-3790. https://doi.org/10.1021/es702952p

[16] Zhang, T. and Sun, D. (2013) Removal of Arsenic from Water Using Multifunctional Micro-/Nano-Structured $\mathrm{MnO}_{2}$ Spheres and Microfiltration. Chemical Engineering Journal, 225, 271-279. https://doi.org/10.1016/j.cej.2013.04.001

[17] Guana, X., Wang, J. and Chusueid, C. (2008) Removal of Arsenic from Water Using Granular Ferric Hydroxide; Macroscopic and Microscopic Studies. Journal of Hazardous Materials, 156, 178-185. https://doi.org/10.1016/j.jhazmat.2007.12.012

[18] Hussein, F. and Abu-Zahra, N. (2016) Synthesis, Characterization and Performance of Polyurethane Foam Nanocomposite for Arsenic Removal from Drinking Water. Journal of Water Process Engineering, 13, 1-5. https://doi.org/10.1016/j.jwpe.2016.07.005

[19] Szycher, M. (1999) Szycher's Handbook of Polyurethanes. CRC Press, Boca Raton.

[20] Hussein, F. and Abu-Zahra, N. (2016) Extended Performance Analysis of Polyurethane-Iron Oxide Nanocomposite for Efficient Removal of Arsenic Species from Water. Water Science and Technology. Water Supply, 17, 889-896. https://doi.org/10.2166/ws.2016.188

[21] Hussein, F. (2016) Synthesis and Performance Analysis of Polyurethane Foam Nanocomposite for Arsenic Removal from Drinking Water. Theses and Dissertations. University of Wisconsin Milwaukee, Milwaukee, Wisconsin, Paper 1154.

[22] Nguyen, T., Vigneswaran, S., Ngo, H., Pokhrel, D. and Viraraghavan, T. (2006) Iron-Coated Sponge as Effective Media to Remove Arsenic from Drinking Water. Water Quality Research Journal of Canada, 41, 164-170.

[23] Mayo, J.T., Yavuz, C., Yean, S., Cong, L., Shipley, H., Yu, W., Falkner, J., Kan, A., Tomson, M. and Colvin, V.L. (2007) The Effect of Nanocrystalline Magnetite Size on Arsenic Removal. Science and Technology of Advanced Materials, 8, 71-75. https://doi.org/10.1016/j.stam.2006.10.005

[24] Yavuz, C.T., Mayo, J.T. and Yu, W.W. (2006) Low-Field Magnetic Separation of Monodisperse $\mathrm{Fe}_{3} \mathrm{O}_{4}$ Nanocrystals. Science, 314, 964-967. https://doi.org/10.1126/science.1131475

[25] Lagergren, S. (1889) To the Theory of So-Called Adsorption of Dissolved Substances. The Royal Swedish Academy of Sciences, 24, 1-39.

[26] Ramesh, A., Hasegawa, H., Maki, T. and Ueda, K. (2007) Adsorption of Inorganic and Organic Arsenic from Aqueous Solutions by Polymeric Al/Fe Modified Montmorillonite. Separation and Purification Technology, 56, 90-100. 
https://doi.org/10.1016/j.seppur.2007.01.025

[27] Guo, X. and Chen, F. (2005) Removal of Arsenic by Bead Cellulose Loaded with Iron Oxyhydroxide from Groundwater. Environmental Science \& Technology, 39, 6808-6818. https://doi.org/10.1021/es048080k

[28] Thirunavukkarasu, O.S., Viraraghavan, T. and Subramanian, K.S. (2003) Arsenic Removal from Drinking Water Using Granular Ferric Hydroxide. Water $S A, 29$, 161-170. https://doi.org/10.4314/wsa.v29i2.4851

[29] Kundu, S. and Gupta, A.K. (2005) Sorption Kinetics of As(V) with Iron-Oxide-Coated Cement-A New Adsorbent and Its Application in the Removal of Arsenic from Real-Life Groundwater Samples. Journal of Environmental Science and Health A. 40, 2227-2246. https://doi.org/10.1080/10934520500234767

[30] Kundu, S. and Gupta, A.K. (2006) Adsorptive Removal of As(III) from Aqueous Solution Using Iron Oxide Coated Cement (IOCC): Evaluation of Kinetic, Equilibrium and Thermodynamic Models. Separation and Purification Technology, 51, 165-172. https://doi.org/10.1016/j.seppur.2006.01.007

Submit or recommend next manuscript to SCIRP and we will provide best service for you:

Accepting pre-submission inquiries through Email, Facebook, LinkedIn, Twitter, etc. A wide selection of journals (inclusive of 9 subjects, more than 200 journals)

Providing 24-hour high-quality service

User-friendly online submission system

Fair and swift peer-review system

Efficient typesetting and proofreading procedure

Display of the result of downloads and visits, as well as the number of cited articles

Maximum dissemination of your research work

Submit your manuscript at: http://papersubmission.scirp.org/

Or contact jmmce@scirp.org 